\title{
ANTIBACTERIAL EFFECT OF TWO BLEACHING AGENTS: IN VIVO STUDY
}

\author{
Dalia M Abu-Elmagd* and Ahmed Z El-Hoshy**
}

\begin{abstract}
Objective: To investigate the antibacterial effect of two commercially available bleaching agents in vivo.

Materials and Methods: 30 volunteers were divided into 3 groups, a control group (chlorhexidine) and 2 treatment groups (Nite White ACP and Nite White ACP Turbo bleaching gels). Stimulated whole saliva samples were collected at baseline, after 1 and 3 applications and 14 days post-treatment. Total count of aerobic bacteria was determined.

Results: For all groups there was a statistically significant decrease in mean count of aerobic bacteria compared to baseline through all periods of the study. After 1 application and 3 applications, there was no statistically significant difference between mean percentage reductions in bacterial counts of the three groups. After 14 days, Nite White ACP Turbo showed the statistically significantly highest mean percentage reduction, followed by Nite White ACP group, then the control group.
\end{abstract}

Conclusion: Bleaching agents can reduce the total count of aerobic bacteria in saliva in vivo.

\section{INTRODUCTION}

There's nothing that radiates health, happiness and even success like a sparkling white smile. So it's no wonder many people choose whitening to improve the appearance of their teeth. In fact, whitening is one of the least expensive cosmetic remedies available to enhance a faded smile. It can be done at home or at your dentist's office, using a variety of products and techniques ${ }^{1,2}$.The application technique of home vital tooth bleaching systems depends on a mouth guard to keep the bleaching agent in contact with tooth surfaces to be bleached ${ }^{3}$. Home vital bleaching commonly utilize carbamide peroxide to deliver a more stable form of hydrogen peroxide, the active bleaching agent. Intraorally, carbamide peroxide dissociates into hydrogen peroxide and urea. Hydrogen peroxide is

* Professor, Department of Operative Dentistry, King Abdulaziz University, Faculty of Dentistry, Jeddah, Saudi Arabia and Cairo University, Faculty of dentistry, Cairo, Egypt

** Associate Professor, Department of Operative Dentistry, Cairo University, Faculty of Dentistry, Cairo, Egypt 
a non toxic, non allergic antibacterial agent eligible of killing a broad range of microorganisms. Urea is a non toxic bacteriostatic agent capable of dissolving necrotic tissue, healing wounds more quickly ${ }^{4,5}$.

Chlorhexidine is one of the most topical antibacterial agents used in dentistry. It has the ability to reduce plaque and affect cariogenic bacteria ${ }^{6}$. It is a wide spectrum antimicrobial agent, acting against both aerobic and anaerobic bacteria. Chlorhexidine has the property of substantivity which consists of maintaining its antibacterial action for a long lasting period when adhered to anionic substrates, being slowly released as its concentration decreased ${ }^{7}$.

Applying the bleaching agents can have benefits other than whitening the teeth. Their antibacterial effect can help shifting the bacterial ecology to a more favorable one thus promoting oral health. Since it is widely used it is important to study its side effects as well as its benefits. Many studies have been conducted to determine the effect of bleaching on enamel and dentine mineral content ${ }^{8}$. However, few research reports have been found that focus the effect of bleaching agents on oral microbiota. Hence, this study was carried to assess the antibacterial effect of two bleaching agents.

\section{MATERIALS AND METHODS}

\section{Materials}

Two bleaching materials, Nite White ACP, Dicuss Dental (16\% carbamide peroxide, potassium nitrate, fluoride, and amorphous calcium phosphate) and Nite White ACP Turbo, Discusss Dental (6\% hydrogen peroxide, potassium nitrate, fluoride, and amorphous calcium phosphate). Chlorhexidine, Hexitol mouthwash, The Arab Drug Company $(0.125 \%$ chlorhexidine $\mathrm{HCl})$ was used as control. Blood agar (Heart muscle, Infusion from (solids), pancreatic digest of casein, yeast extract, sodium chloride, agar). Fluoride free dentifrice Sensodyne Original, GlaxoSmithKline (10\% strontium chloride hexahydrate).

\section{Methods}

\section{Volunteers selection:}

The protocol of this in vivo study was approved by the ethics committee of Cairo Dental Faculty and with the informed consent of patients. Thirty volunteers were enrolled in the study. The volunteers who were candidates for bleaching treatment were dental students, making a homogenous sample with regard to adequate oral hygiene and motivation to oral health ${ }^{3}$. Each volunteer was informed about the goals, benefits, and possible risks associated with this experiment. At the screening visit all the volunteers were evaluated to decide if they agree the inclusion/exclusion criteria.

\section{Inclusion/ exclusion criteria:}

\section{Inclusion Criteria:}

- Caries-free and unrestored facial surfaces of the six anterior teeth and the first premolars ${ }^{9,5}$.

- Age range from 20-25 years.

- The will to complete the study and have their teeth whitened ${ }^{10}$.

- Ability to return for periodic examination and saliva collection ${ }^{9}$.

- The will to refrain from chewing gum ${ }^{11}$.

- The ability to avoid snacks in between meals during the study period.

\section{Exclusion criteria:}

- Medical history that contraindicates dental treatments ${ }^{10}$.

- Evidence of dry mouth or salivary gland disorders.

- Systemic disease known to affect oral health $^{12,13,14}$

- Taking antibiotics or any drug that affect salivary flow rate or oral microbiota three months prior to the start of the study $y^{3,13-16}$ 
- Pregnant or nursing women ${ }^{3,9,12,13,15}$

- Allergy to chlorhexidine and/or hydrogen peroxide ${ }^{15}$.

- Significant periodontal disease ${ }^{5}$.

- Sensitivity to air blast from air-water syringe (dentine sensitivity $)^{3,5,15}$

- Fixed or removable dentures or orthodontic appliances ${ }^{3,13,15,17}$

- Tetracycline stained teeth.

- Smokers $^{3,13,15,18}$

\section{General instructions:}

Two weeks before the experiment all volunteers were refrained from using all oral hygiene products including fluoride containing tooth-paste, and throughout the whole study period. They were instructed to brush their teeth twice a day, in the morning and evening using fluoride free tooth paste (Sensodyne Original) to prevent the fluoride antibacterial effect that may overlie the effect of bleaching agents and the Bass dental hygiene technique to standardize tooth brushing method. One week prior to the initiation of the active treatment a thorough professional oral prophylaxis was done. This phase lasted for two weeks ${ }^{3}$.The volunteers were instructed to avoid snacks in between meals and chewing gum during the study period.

\section{Volunteers grouping:}

They were divided to 3 groups of ten each. For the control group volunteers rinsed before bedtime with $15 \mathrm{ml}$ Hexitol mouthwash for 30 seconds and expectorate. This was repeated for 3 successive nights. While for the other 2 test groups volunteers, they used Nite White ACP or Nite White ACP Turbo bleaching gels in custom made bleaching trays for both arches according to manufacturer instructions overnight for 3 successive nights.

\section{Saliva collection:}

Prior to starting the treatment (baseline), whole saliva samples were collected in sterile calibrated screw-capped containers ${ }^{4}$ from each of the volunteers after stimulation in the morning ${ }^{3}$, in order to assess the total level of aerobic bacteria in saliva. The volunteers were asked to avoid any food or drink (except water) or take any medication in the morning prior to sampling ${ }^{11}$. The volunteers chewed on a piece of unflavored paraffin wax until it attained soft consistency (about 1minute). They swallowed the first portion of saliva ${ }^{3,19}$, then they chewed for additional 5 minutes, using both sides of the mouth and intermittently spit saliva into the calibrated sterile screw-capped containers $\mathbf{s}^{3,4,17,20,21}$. This was done before bleaching application after the first and third bleaching applications and 14 days post treatment ${ }^{20}$. Four saliva samples were collected from each volunteer, so 40 samples were collected from each group.

\section{Microbiological study:}

The total count of aerobic bacteria in the saliva was determined before, during and after treatment using blood agar plates ${ }^{3,4,15,20}$. After incubation the colonies on the plates were counted using magnifying glass, the count of total aerobic bacteria was expressed as the number of colony forming units per milliliter (CFU/ml) of saliva ${ }^{3,4,17,20,22-27}$. All samples were processed directly after collection.

\section{Culturing procedures:}

A pilot study was conducted to determine the suitable dilution to obtain countable plates using 10 -fold serial dilutions method ${ }^{3,4,15,21,25}$. The dilution $1 / 1000$ and $1 / 10000$ produced countable plates, so the two dilutions were used.

\section{Inoculation procedures:}

For each sample the 2 dilutions were cultured in duplicate ${ }^{3}$ and the mean $\mathrm{CFU} / \mathrm{ml}$ saliva was calculated for each sample. From each dilution, 
$100 \mu 1$ were transferred by an automatic micropipette from the test tube onto the agar surface to be inoculated. The samples were dispersed on the agar surface using sterile bent glass rods ${ }^{4}$, which were used to provide smooth surface without scratching the agar surface giving a homogenous growth. All the cultivation procedures were done away from air currents and in area no more than $10 \mathrm{~cm}$ away from a glowing torch.

\section{Incubation procedures:}

After inoculation all plates were incubated aerobically at $37^{\circ} \mathrm{c}$ for $24-48$ hours ${ }^{15}$.

\section{Bacterial count:}

The number of viable cells was counted by viable count technique using the following equation:

Number of colonies $/ \mathrm{ml}(\mathrm{CFU} / \mathrm{ml})=$ Number of colonies counted $x$ Inverse of dilution $x$ Inverse of the cultured volume $(\mathrm{ml})$.

For each sample we had four counts ( 2 for each dilution $1 / 1000$ and $1 / 10000$ ), a mean count was obtained for each dilution ${ }^{17}$.

\section{Statistical analysis}

Data were presented as mean and standard deviation (SD) values. ANOVA (Analysis of Variance) was used to compare between the three groups. Tukey's post-hoc test was used for pair-wise comparison between the means when ANOVA test is significant. Paired t-test was used to study the changes by time in each group. The significance level was set at $\mathrm{P} \leq 0.05$. Statistical analysis was performed with SPSS 16.0 (SPSS, Inc., Chicago, IL, USA), Statistical Package for Scientific Studies for Windows.

\section{RESULTS}

The results of this study showed a stastistically significant decrease in the mean count of aerobic bacteria for the three groups through all periods, compared to baseline at $\mathrm{P} \leq 0.05$. Table (1) and figure (1) represents the mean, standard deviation (SD) values, results of ANOVA and Tukey's tests for comparison between percentage reductions in the count of aerobic bacteria of the three groups. However, the difference became statistically significant at 14 days after treatment, where Nite White ACP Turbo group showed the statistically significant highest mean percentage reduction. This was followed by Nite White ACP group, chlorhexidine group showed statistically significant lowest mean percentage reduction. The difference in percentage reduction in bacterial count was considered significant at $\mathrm{P} \leq 0.05$.

The percentage reduction was calculated as:

Count (before) - Count (after)

Count (before) x 100

TABLE (1) The mean, standard deviation (SD) values, results of ANOVA and Tukey's tests for comparison between percentage reductions in bacterial counts of the three groups:

\begin{tabular}{|c|c|c|c|c|c|c|c|}
\hline \multirow{2}{*}{ Group } & \multicolumn{2}{|c|}{ Control } & \multicolumn{2}{c|}{ Nite White } & \multicolumn{2}{c|}{ Nite white Turbo } & \multirow{2}{*}{ P- Value } \\
\cline { 2 - 8 } & Mean\% & SD \% & Mean\% & SD\% & Mean\% & SD\% & \\
\hline Baseline- 1 application & 44.3 & 7.5 & 45.9 & 5.4 & 49.4 & 17.5 & 0.605 \\
\hline Baseline- 3 applications & 66.1 & 8.6 & 65.9 & 4.6 & 70.4 & 19.1 & 0.663 \\
\hline Baseline- 14 days & $13.6^{\mathrm{c}}$ & 5.2 & $21.1^{\mathrm{b}}$ & 7.9 & $32.3^{\mathrm{a}}$ & 17.3 & $0.004^{*}$ \\
\hline
\end{tabular}

* Significant at $P \leq 0.05$, means with different letters are statistically significantly different according to Tukey's test 
After 1 application and 3 applications, there was no statistically significant difference between mean percentage reductions in bacterial counts of the three groups.

After 14 days, Nite White Turbo group showed the statistically significant highest mean percentage reduction. This was followed by Nite White group. Control group showed the statistically significant lowest mean percentage reduction.

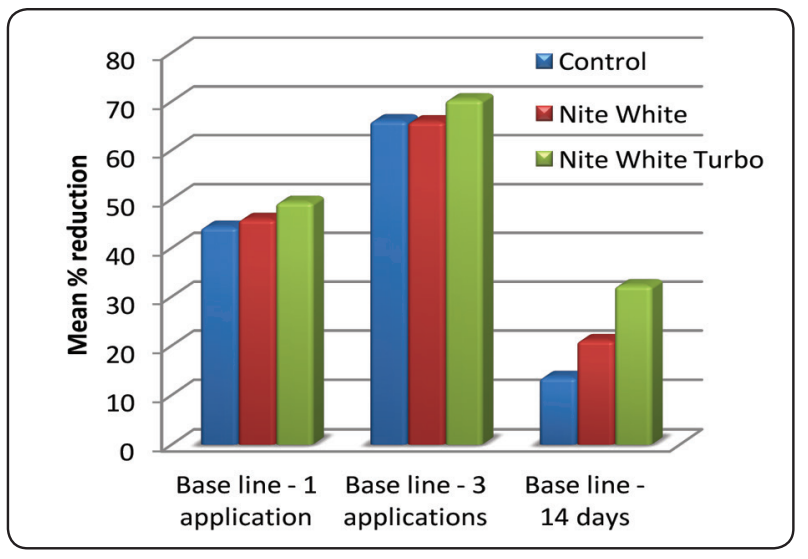

Fig. (1) Bar chart for comparison between mean percentage reductions in count of aerobic bacterial of the three groups.

\section{DISCUSSION}

The results of this in vivo study showed that bleaching gels used in custom-fitted tray and the chlorhexidine mouth rinse reduced the total count of aerobic bacteria in saliva, after 1, 3 and 14 days post-treatment.

These results were in agreement with Benley et $\mathrm{al}^{4}$, who found that $10 \%$ carbamide peroxides solutions reduced the levels of Lactobacilli in vivo, but did not affect the levels of Mutans Streptococci. In addition Amaechi et $\mathrm{al}^{22}$ found that cabamide peroxide is capable of killing bacteria harboring non-cavitated caries lesions. It was also in agreement with Kraigher et $\mathrm{al}^{28}$ and Lazarchik et $\mathrm{al}^{29}$ who claimed that $10 \%$ carbamide peroxide bleaching agents had an antimicrobial effect on cariogenic bacteria as a result of the direct chemical effect of hydrogen peroxide.
In opposition. Alkamin et $\mathrm{al}^{3}$, found that different bleaching agents did not change the oral cavity Mutans Streptococci counts. Also Haak et $\mathrm{al}^{20}$ found that $9 \%$ hydrogen peroxide gel application does not reduce the quantity of Mutans Streptococci and Lactobacilli in saliva. In the two studies the volunteers used bleaching agents for a short period at each application; they wear the bleaching trays for 1 hour in the first study and for 30 minutes in the second study. In this study each application lasted for at least 6 hours, as the volunteers were instructed to wear the bleaching trays over night.

For the control group the reduction of the bacterial count was due to the antimicrobial activity of chlorhexidine. The antimicrobial effect is mediated by several mechanisms. It binds electrostatically to negatively charged sites on bacteria (phosphate groups on bacterial cell wall). By attaching to the bacterial cytoplasmic membrane, chlorhexidine causes lose of the osmotic balance, resulting leakage of intracellular material. It also binds to hydroxyapatite and soft tissues, changing their electric field to compete with bacterial binding $^{30-32}$. The unique advantage of chlorhexidine is its capability to bind to salivary pellicle thus prolonging its retention in the oral cavity ${ }^{33}$.

For the test groups the reduction in the total count of aerobic bacteria may be due the antibacterial effect of hydrogen peroxide which might have been released into saliva during bleaching. Previous studies supported the release of hydrogen peroxide in saliva during the application of nightguard vital bleaching ${ }^{9,34-38}$.

\section{CONCLUSION}

Nightguard vital bleaching may have the ability to reduce the total count of aerobic bacteria during and up to 14 days after their application. Bleaching gels may have an antibacterial effect in addition to their whitening effect. 


\section{REFERENCES}

1. Kwon SR and Phillip WW: Review of the mechanism of tooth whitening. Journal of Esthetic and Restorative dentistry, 27(5), 240-257, 2015.

2. Bazi JZ, Bindo MJF, Rashed RN, Mazur MF, Vieira S, de Souza E M: The effect of at-home bleaching and toothbrushing on removal of coffee and cigarette smoke stains and color stability of enamel. Journal of American Dental Association, May; 143 (5), e1-e7: 2012.

3. Alkamin YT, Sartorelli R, Florio FM, Basting RT: Comparative study of the effects of two bleaching agents on oral microbiota. Journal of Operative Dentistry, 30(4): 417-423; 2005.

4. Bentley C, Leonard R, Crawford J: Effects of whitening agents containing carbamide peroxide on cariogenic bacteria. Journal of Esthetic Dentistry, 12(1): 33-37; 2000

5. Matis BA, Gaiao U, Blackman D, Schultz FA, Eckert GJ: In vivo degradation of bleaching gel used in whitening teeth. Journal of American Dental Assocation, Feb;130: 227-235;1999.

6. Steinberg D, Abid-El-Raziq D, Heling I: In vitro antibacterial effect of RC-Prep components on streptococcus sobrinus. Journal of endodontics and Dental Traumatolog, Aug; 15 (4): 171-174; 1999.

7. Pinheiro CR, Nishiyama CK, Hussne RP, Botolo MV, Sipert CR, Torres SA. Antimicrobial activity of chlorhexidine and calcium hydroxide gels: an in vitro evaluation. Perspectives in Oral Science, 1(2):13-18; 2009.

8. Do Amaral FLB, Sasaki RT, da Silva TCR, Franca FMG, Florio FM, Basting RT: The effects of home-use and inoffice bleaching treatments on calcium and phosphorus concentrations in tooth enamel. Journal of American Dental Association, Jun; 143(6), 580-586: 2012.

9. Matis BA, Yousef M, Cochran MA, Eckert GJ: Degradation of bleaching gels in vivo as a function of tray design and carbamide peroxide concentration. Journal of Operative Dentistry, 27:12-18; 2002.

10. Wille T, Pesun IJ, Combe EC, Lindquist GC, Hodges JS: A clinical pilot study of the time- dependent composition of tooth bleaching systems. Journal of Oral Rehabilitation, 30: 510-514; 2003.

11. Smith CA, Higham SM, Smith PW, Verran J: The effect of chewing urea- containing gum on plaque acidogenic and alkaligenic parameters. Caries Research, 38:124-129; 2004.
12. Hoffmann T, Bruhn G, Richter S, Netuschil L, Brecx M: Clinical controlled study on plaque and gingivitis reduction under long-term use of low- dose chlorhexidine solutions in a population exhibiting good oral hygiene. Clinical Oral Investigations, 5: 89-95; 2001.

13. Lorenz K, Bruhn G, Heumann L, Netuschil L, Brecx M, Hoffmann T: Effect of two new chlorhexidine mouthrinses on the development of dental plaque, gingivitis and discoloration. A randomized, investigator- blind, placebocontrolled, 3-week experimental gingivitis study. Journal of Clinical Periodontology, 33: 561-567; 2006.

14. Ercan E, Dulgergil T, Yavuz I: The effects of antibacterial solutions on microorganisms isolated from infected root canals in vivo. Journal of Biotechnology, 1: 149-156; 2006.

15. Franz-Montan M, Ramacciato JC, Rotrigues JA, Marchi GM, Rosalen PL, Groppo FC: The effect of combined bleaching techniques on oral microbiota. Indian Journal of Dental Research, 20 (3): 304- 307; 2009.

16. Slot DE, Lindeboom R, Rosena NAM and Timmerman MF, Van der Weijden GA: The effect of $0.12 \%$ chlorhexidine dentirifice gel on plaque accumulation: a 3-day nonbrushing model. International Journal of Dental Hygiene, 5; 45-52; 2007.

17. Hegde PP, Ashok Kumar BR, Ankola VA: Dental caries experience and salivary levels of streptococcus mutans and lactobacilli in 13-15 years old children of Belgaum city, Karnataka. Journal of Indian Society of Pedodontics and Preventive Dentistry, 23(1): 23-26; 2005.

18. de Gues JL, Bersezio C, Urrutia J, Yamada T, Fernandez E, loguercio AD, Reis A, Kossatz S: Effectiveness of and tooth sensitivity with at-home bleaching in smokers. Journal of American Dental Association, Apr; 146(4): 233-240; 2015.

19. Motisuki C, Lima LM, Spolidorio DMP, Santos-Pinto L: Influence of sample type and collection method on Streptococcus mutans and Lactobacillus spp. Counts in the oral cavity. Archives of Oral Biology, 50: 341-345; 2005.

20. Haak R, Wicht MJ,Faber FJ, Noack MJ: Hydrogen peroxide bleaching does not reduce cariogenic microorganisms in saliva. IADR/AADR/CADR 83rd general session (March 9-12,2005)

21. Tamaki Y, Nomura Y, Takeuchi H, Ida H, Arakwa H, Tsurumoto A, Kumagai T, Hanada N: Study of the clinical usefulness of a dental drug system for selective reduction of Mutans Streptococci using a casr series. Journal of Oral Science, 48 (3): 111-116; 2006. 
22. Amaechi BT, Solis V, Lozano-Pineda J, Summitt J, Barghi $\mathrm{N}$ : Antimicrobial effects of carbamide peroxide bleaching gel in non-cavitated fissure caries lesions. Caries Research, 39(4): 330-331; 2005.

23. Sekino S, Ramberg P, Uzel NG, Socransky S, Lindhe $\mathrm{J}$ : Effect of various chlorhexidine regimens on salivary bacteria and de novo plaque formation. Journal of Clinical Periodontology, Oct; 30(10): 919-925; 2003.

24. de Albuquerque RFJR, Head TW, Mian H, Rodrigo A, Muller K, Sanches K, Ito IY: Reduction of salivary S. aureus and Mutans group of Streptococci by a preprocedural chlorhexidine rinse and maximal inhibitory dilutions of chlorhexidine and cetylpyridinium. Quintessence International, Sep; 35(8): 635-640; 2004.

25. Tomas I, Cousido MC, Tomas M, Limeres J, GarciaCabellero L, Diz P: In vivo bactericidal effect of $0.2 \%$ chlorhexidine but not $0.12 \%$ on salivary obligate anaerobes. Archives of Oral Biology, Dec; 53(12):11861191; 2008.

26. Paula VAC, Modesto A, Santos KRN, Gleiser R: Antimicrobial effects of the combination of chlorhexidine and Xylitol. British Dental Journal, Dec 18; 209(12): E19; 2010 .

27. Delgato RJR, Gasparoto TH, Sipert CR, Pinheiro CR, Moraes IG, Garcia RB, Bramante CM, Campanelli AP, Bernardineli N: Antimicrobial effects of calcium hydroxide and chlorhexidine on Enterococcus faecalis. Journal of Endodontics, Aug; 36(8): 1389-1393; 2010

28. Kraigher A, Van der Veen MH, Potocnik I: Caries occurrence in rats after bleaching with $10 \%$ carbamide peroxide in vivo. Caries Research, 40: 77-80; 2006.

29. Lazarchik DA, Haywood VB: Use of tray applied $10 \%$ carbamide peroxide gels for improving oral health in patients with special-care needs. Journal of American Dental Association, Jun; 141 (6): 639-646; 2010.

30. Dogan S, Gunay H, Leyhausen G, Geurtsen W: Effects of low-concentrated chlorhexidine on growth of streptococcus sobrinus and primary human gingival fibroblast. Clinical Oral Investigations, 7: 212-216; 2003.

31. Battaqlia A: The Bass technique using a specially designed tooth brush. International Journal of Dental Hygiene, Aug; 6(3): 183-187; 2008

32. Helling I, Chandler NP: Antimicrobial effect of irrigant combinations within dentinal tubules. International Endodontic Journal, 31: 8-14; 1998.

33. Steinberg D, Heling I, Daniel I, Ginsburg I: Antibacterial synergistic effect of chlorhexidine and hydrogen peroxide against streptococcus sobrinus, streptococcus faecalis and staphylococcus aureus. Journal of Oral Rehabilitation, 26: 152-156; 1999.

34. Wattanapayungkul P, Matis BA, Cochran MA, Moore BK: A clinical study of the effect of pellicle on the degradation of $10 \%$ carbamide peroxide within the first hour. Quintessence International, Nov; 30(11): 737-741; 1999.

35. Hanning C, Zech R, Henze E, Dorr-Tolui R, Attin T: Determination of peroxides in saliva-kinetics of peroxide releaseinto saliva during home bleaching with whitestrips and Vivastyle. Archives of Oral Biology, 48: 559-566; 2003.

36. Hanning C, Zech R, Henze E, Dreier S, Attin T: Peroxide release into saliva from five different home bleaching systems in vivo. American Journal of Dentistry, Feb; 18(1):13-18; 2005.

37. Hanning C, Willenbucher S, Becker K, Mahony C, Attin $\mathrm{T}$ : Recovery of peroxide in saliva during home bleachinginfluence of smoking. Journal of Oral Rehabilitation, 33: 533-541; 2006.

38. Dawson PF, Sarif MO, Smith AB, Brunton PA: A clinical study comparing the efficacy and sensitivity of home vs combined whitening. Journal of Operative Dentistry, 36(5):460-6; 2011.

39. A clinical study comparing the efficacy and sensitivity of home vs combined whitening. Dawson PF, Sarif Mo, Smith AB, Brunton PA .Oper Dent 2011; 36(5):460-6. 